ARTICLE

DOI: $10.1038 / s 41467-017-00487-7$

OPEN

\title{
Towards designer organelles by subverting the peroxisomal import pathway
}

\author{
Laura L. Cross (1) 1,2,3, Rupesh Paudyal (10) 3,4, Yasuko Kamisugi (10) 4,5, Alan Berry (1) 1,3, Andrew C. Cuming (1) 4,5, \\ Alison Baker (1) ${ }^{1,3,4} \&$ Stuart L. Warriner (1) ${ }^{1,2}$
}

The development of 'designer' organelles could be a key strategy to enable foreign pathways to be efficiently controlled within eukaryotic biotechnology. A fundamental component of any such system will be the implementation of a bespoke protein import pathway that can selectively deliver constituent proteins to the new compartment in the presence of existing endogenous trafficking systems. Here we show that the protein-protein interactions that control the peroxisomal protein import pathway can be manipulated to create a pair of interacting partners that still support protein import in moss cells, but are orthogonal to the naturally occurring pathways. In addition to providing a valuable experimental tool to give new insights into peroxisomal protein import, the variant receptor-signal sequence pair forms the basis of a system in which normal peroxisomal function is downregulated and replaced with an alternative pathway, an essential first step in the creation of a designer organelle.

\footnotetext{
${ }^{1}$ Astbury Centre for Structural Molecular Biology, University of Leeds, Leeds LS2 9JT, UK. ${ }^{2}$ School of Chemistry, University of Leeds, Leeds LS2 9JT, UK. ${ }^{3}$ School of Molecular and Cellular Biology, University of Leeds, Leeds LS2 9JT, UK. ${ }^{4}$ The Centre for Plant Sciences, University of Leeds, Leeds LS2 9JT, UK. ${ }^{5}$ School of Biology, University of Leeds, Leeds LS2 9JT, UK. Laura L. Cross and Rupesh Paudyal contributed equally to this work. Correspondence and requests for materials should be addressed to A.Ba. (email: a.baker@leeds.ac.uk) or to S.L.W. (email: s.l.warriner@leeds.ac.uk)
} 
S ubcellular compartmentalization is a fundamental process used extensively in eukaryotes to separate potentially incompatible biological reaction pathways and processes, as well as enabling locally high concentrations of key pathway components or the segregation of harmful products. The creation of a bespoke intracellular compartment would be a highly desirable synthetic biology tool, as it would enable non-natural pathways to be isolated from other cellular processes. Such isolation could lead to increased yields of synthetic proteins in biotechnology applications and prevention of adverse effects on existing metabolic pathways, as well as alteration of post-translational modifications of high-value protein products. In order to create such compartments, it will be necessary to create tailored and specific delivery systems by manipulating the extensive cellular protein trafficking networks that deliver cargo selectively to organelles. Here we show that it is possible to remodel the protein-protein interactions that control peroxisomal protein import to create an orthogonal signal-receptor pair that is functional in vivo. This allows switching of the selectivity of protein import to effectively 'hijack' the function of the pre-existing peroxisome, simultaneously downregulating import of native peroxisomal proteins - an essential first step towards creating a designer organelle that could exist in parallel with 'normal' peroxisomes.

The peroxisome is an ideal starting point for the development of a customizable compartment: ${ }^{1}$ it does not contain a genome, so all proteins are imported from the cytosol, and proteins are imported in a fully folded state through a transient pore, so peroxisomes retain a barrier to the cytosol ${ }^{2}$. The peroxisome has already been identified as a compartment for biotechnological exploitation: non-peroxisomal biosynthetic enzymes can be directed to the yeast peroxisome and still retain function ${ }^{3-5}$, while targeting synthetic pathways to peroxisomes can increase the production of fatty-acid-derived alcohols, alkanes, and olefins by up to $700 \%{ }^{6}$.
Protein targeting to peroxisomes depends on recognition of a short peptide signal sequence by a receptor that cycles between the cytosol and the peroxisome. A C-terminal peroxisomal targeting signal 1 (PTS1) is the predominant signal in peroxisomal proteins, and this is recognized by the receptor peroxin 5 (PEX5). PEX5 binds PTS1, escorts the PTS1-containing protein to the peroxisomal membrane, and then (together with peroxisomal membrane proteins) inserts into the membrane, creating a dynamic pore through which the peroxisomal protein is delivered to the organellar lumen ${ }^{7-9}$. PEX5 is recycled back to the cytosol in a process driven by ubiquitination and ATP hydrolysis $^{10}$. PTS1 is not a single motif but rather a family of sequences and, while a C-terminal tripeptide sequence of [S/A]-[K/R]-[L/M] is optimal, a range of non-consensus residues can be tolerated in the correct upstream context ${ }^{11-13}$.

PEX5 is a modular protein: the C-terminal domain recognizes PTS1 within a funnel-shaped pocket created by $7 \alpha$-helical tetratricopeptide repeats (TPRs) ${ }^{14}$, while the $\mathrm{N}$-terminal domain of PEX5, which is natively unstructured ${ }^{15}$, is responsible for the docking, cargo delivery, and recycling functions of the receptor ${ }^{10}$. We hence envisioned that the C-terminal domain of PEX5 could be mutated to produce a variant with orthogonal targeting sequence recognition $\left(\mathrm{PEX} 5^{\star}\right)$ without altering the import competence of the variant receptor. The PEX5*-PTS1* pair was discovered by assessing the binding of a range of variants of the C-terminal domain of Arabidopsis thaliana PEX5 (AtPEX5C) with a library of pentapeptides (Fig. 1a). PEX $5^{\star}$ shows greatly reduced binding to a representative PTS1 peptide and a 300 -fold increase in affinity for an orthogonal peptide sequence $\left(\mathrm{PTS}^{*}\right)$. PTS1 ${ }^{\star}$ has low affinity for the naturally occurring PEX5 receptor. Following optimization, the C-terminal $\mathrm{PEX} 5^{\star}$ sequence was combined with the N-terminal domain of PEX5 from the moss Physcomitrella patens (Phypa PEX5N) to create a fully functional $\mathrm{PEX} 5^{\star}$ receptor (Fig. 1a). Concomitant expression of $\mathrm{PEX} 5^{\star}$ with a cargo protein bearing $\mathrm{PTS} 1^{\star}$ results in a

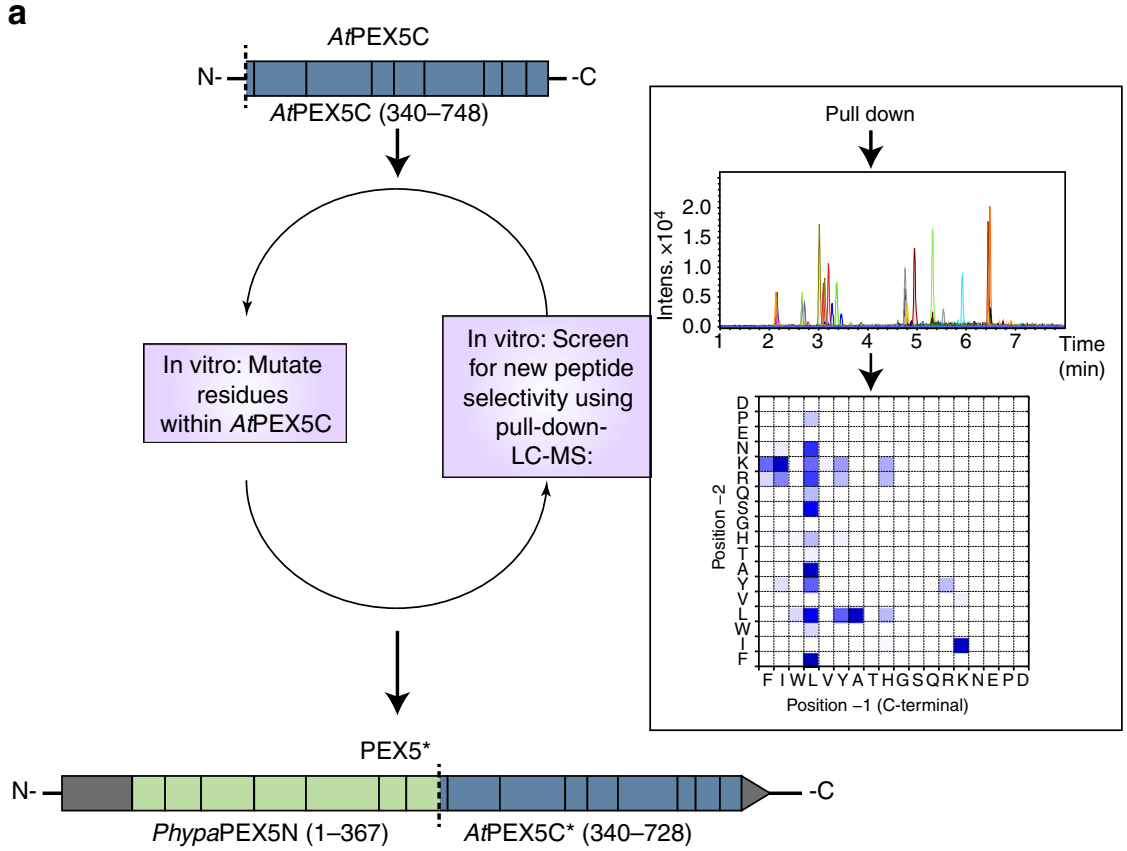

b

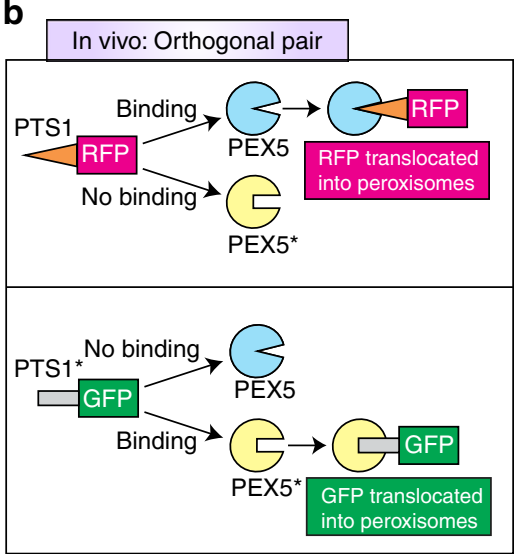

Fig. 1 Strategy for the development of an orthogonal PEX5:PTS1-like interaction. a The C-terminal domain of AtPEX5 (AtPEX5C) was mutated and screened in vitro against a library of peptides to identify binding of non-PTS1 sequences. Once an orthogonal pair of peptide (PTS1 $\left.{ }^{\star}\right)$ and protein (PEX $\left.5^{\star}\right)$ was identified, the mutant AtPEX5C* sequence was then fused to PhypaPEX5N to create a hybrid full-length receptor with altered specificity suitable for in vivo experiments in the moss P. patens (Phypa). b The intracellular localization of fluorescent proteins appended with either a PTS1 or PTS1* sequence was then used to determine the orthogonality of import in vivo 
targeting of the cargo to the peroxisome at the expense of naturally occurring peroxisomal components-a process that was easily visualized in moss cells using fluorescent reporter proteins (Fig. 1b).

\section{Results}

Assaying for protein-binding peptides. The chemical space that can be covered by all possible variants of the receptor and signal sequence is vast (e.g., combined randomization of the two $\mathrm{C}$-terminal PTS1 residues and just six residues within AtPEX5C would result in a library size of $2.6 \times 10^{10}$ variants of peptide and protein), which makes the development of an assay for a $\mathrm{PEX}^{*}-\mathrm{PTS}^{*}$ pair problematic. We reduced the dimensionality of this search by designing modifications to the PEX5 component and rapidly surveying which peptide sequences could be bound by each mutated receptor (Fig. 1a). Site-directed variants of a His $_{6}$-tagged A. thaliana PEX5 PTS1-binding domain (residues 340-728, AtPEX5C) ${ }^{16}$, selected by analysis of known crystal structures, were expressed in Escherichia coli. The purified proteins were incubated with a library of pentapeptides, representing known PTS1 and putative PTS1* sequences. After capture of the receptor-peptide complexes on cobalt affinity resin, the bound peptides were eluted and identified by liquid chromatography-mass spectrometry (LC-MS) analysis. Screening of single-site AtPEX5C variants with the library of peptides was used to identify the most promising AtPEX5C mutations and peptide combinations. These mutations were subsequently combined, thus minimizing the dimensionality of the search (Fig. 1a). This assay enabled both the rapid survey of many potential binding partners for the mutated PEX5, and the analysis of how sequence specificity of binding changed upon introduction of the mutations.

The pentapeptide library sequences were based on YQSKL, which has a nM affinity for the AtPEX5 TPR domain ${ }^{17}$ and is widely used as a model PTS1 peptide ${ }^{14}$. This sequence was randomized at the two $\mathrm{C}$-terminal positions to create a library of sequences, YQSXX, where X represents any amino acid, which was efficiently prepared using split-and-pool solid-phase peptide synthesis. A dansyl fluorophore introduced at the N-terminus of the peptide added hydrophobicity to improve retention in LC-MS analysis. Deconvolution of Leu- and Ile-containing peptides was enabled by preparation of four sub-libraries that separated these isobaric residues for characterization, although all screens were performed on the combined library. Cysteine was excluded from the library design to avoid any complications from disulfide formation, while oxidation of methionine during synthesis meant that methionine-containing peptides were also excluded from the analysis. The final library hence contained 324 sequences.

We first determined the LC retention time of each peptide present in the library using a tandem quadrupole time-of-flight mass spectrometer. By analyzing extracted ion chromatograms based upon the exact (rather than the nominal) masses of the peptide ions ${ }^{18}$, and using LC-MS/MS methods to distinguish positional isomers, all the peptides could be observed in the parent libraries (Supplementary Fig. 1). Unique retention times were determined for 236 of the 324 peptides; however, a lack of HPLC separation meant that the remaining peaks could only be assigned to a pair of positional isomers that co-eluted, for example dansyl-YQSKI and dansyl-YQSIK. While the difference in ionization efficiency between the peptides (up to $\sim 250$-fold between the weakest and the strongest signals) and the presence of overlapping peaks made the method only semi-quantitative, the high sensitivity and ease of the screen enabled rapid comparison of the sequence specificity of variant receptor proteins for the library of peptides.
As anticipated, using the wild-type AtPEX5C receptor domain, the peptides pulled down from the library revealed a strong preference for leucine at the C-terminal (-1) position (Fig. 2a): a characteristic of many native PTS1 sequences ${ }^{19,20}$. A wider variety of residues were observed at the -2 position, with peptides bearing $\mathrm{H}, \mathrm{N}, \mathrm{S}, \mathrm{Q}, \mathrm{P}, \mathrm{W}, \mathrm{T}, \mathrm{A}, \mathrm{Y}, \mathrm{L}$, and $\mathrm{F}$ all being recovered along with the more prototypical $\mathrm{K}$ and $\mathrm{R}$. Bioinformatic tools enable the prediction of the peroxisomal targeting efficiency of sequences (PredPlantPTS1 ${ }^{21}, 22$ ), and peptides within the tested library were ranked based on their peroxisomal targeting prediction score. More than $75 \%$ of the PTS1-predicted peptides with a PredPlantPTS1 score above 0.6 (indicating moderate peroxisomal import) were pulled down by the wild-type AtPEX5C receptor.

Selection of PEX5 $^{*}$ variants. Inspection of a model of the AtPEX5C:PTS1 interaction generated from known crystal structures ${ }^{14,23-26}$ identified residues close to the PTS1-binding site as targets for mutagenesis. Thirty-four receptor variantswere screened (Supplementary Table 1), and the patterns of peptides that were pulled down from the library of 324 peptides were visualized as heat maps (Fig. 2 and Supplementary Figs. 2 and 3). Of particular interest were the mutations D505H and N601A, resulting in AtPEX5C variants that bound to the sequences dansyl-YQSYY and dansyl-YQSFY (Fig. 2b, c). These sequences were not pulled down by wild-type AtPEX5C (Fig. 2a).

To validate and quantify the effect of these mutations, a fluorescence anisotropy (FA) assay ${ }^{17}, 27$ was employed to determine the binding affinity of lissamine-labelled YQSKL and YQSYY to the wild-type AtPEX5C receptor and its variants (lissamine-labelled YQSFY had poor solubility and so investigations of this sequence were not pursued). The affinity of the AtPEX5C receptor for lissamine-YQSKL, determined using the FA assay, was $1.1 \pm 0.6 \mathrm{nM}$ (errors represent the standard deviation of triplicate repeats), while lissamine-YQSYY had only a very weak affinity $(2.7 \pm 0.2 \mu \mathrm{M}$ ) (Fig. $2 \mathrm{a}$ ). By contrast, the $\mathrm{D} 505 \mathrm{H}$ variant of AtPEX5C had an improved affinity of $960 \pm 80 \mathrm{nM}$ for lissamine-YQSYY, while the affinity for lissamine-YQSKL was reduced to $30 \pm 7 \mathrm{nM}$ (Fig. 2b). The N601A variant bound lissamine-YQSYY similarly to wild-type AtPEX5C $(2.3 \pm 0.4 \mu \mathrm{M})$, while the affinity for lissamine-YQSKL was $22 \pm 8 \mathrm{nM}$ (Fig. 2c). Combination of these mutations, to generate $\mathrm{D} 505 \mathrm{H}-\mathrm{N} 601 \mathrm{~A}$, resulted in an even greater change: the affinity for lissamine-YQSYY increased to $603 \pm 70 \mathrm{nM}$, while the affinity for lissamine-YQSKL decreased to $108 \pm 15 \mathrm{nM}$ (Fig. 2d).

As residue D505 is close to the lysine side chain of YQSKL, changing this aspartate residue to histidine should remove this electrostatic interaction and create a pocket more suitable for an aromatic residue. We predicted that further decrease in the negative charge in this area may improve selectivity. Therefore, a $\mathrm{D} \rightarrow \mathrm{T}$ mutation was introduced at a nearby position 507 , creating the variant D505H-D507T-N601A $\left(\right.$ AtPEX5C $\left.{ }^{\star}\right)$. This enhanced the affinity and selectivity for the variant peptide sequence to the extent that lissamine-YQSYY bound with an affinity almost identical to lissamine-YQSKL $(110 \pm 50 \mathrm{nM}$ vs. $97 \pm 20 \mathrm{nM})$ (Fig. 2e). Bioinformatic tools ${ }^{21}, 22$ typically also include the upstream context when predicting the in vivo peroxisomal import competence of a sequence. We hence anticipated that a further improvement in the efficacy of YQSYY would be achievable in vivo by placing it downstream of appropriate residues, to create a high-affinity $\mathrm{PTS}^{\star 28}$.

An optimized PEX5*-PTS1* pair in vivo. With new receptortargeting signal selectivities developed, the functionality of the mutated receptor was tested in vivo in Physcomitrella patens. This 
a
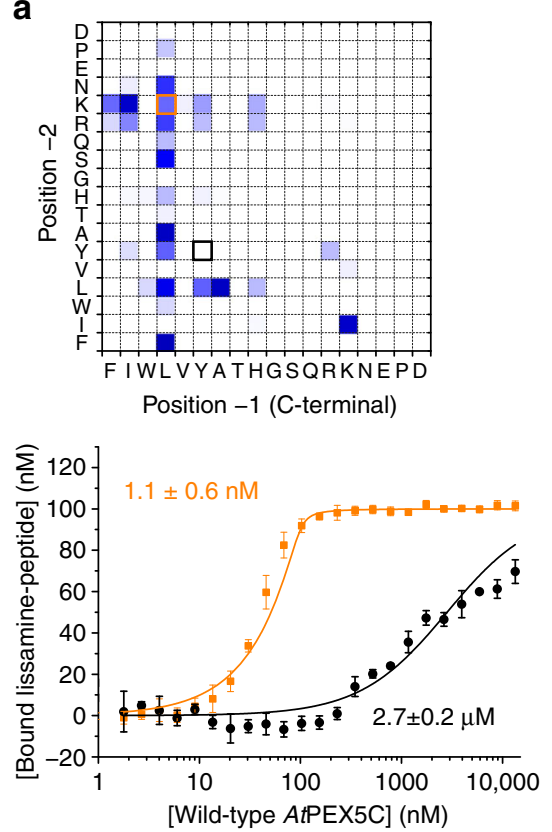

d
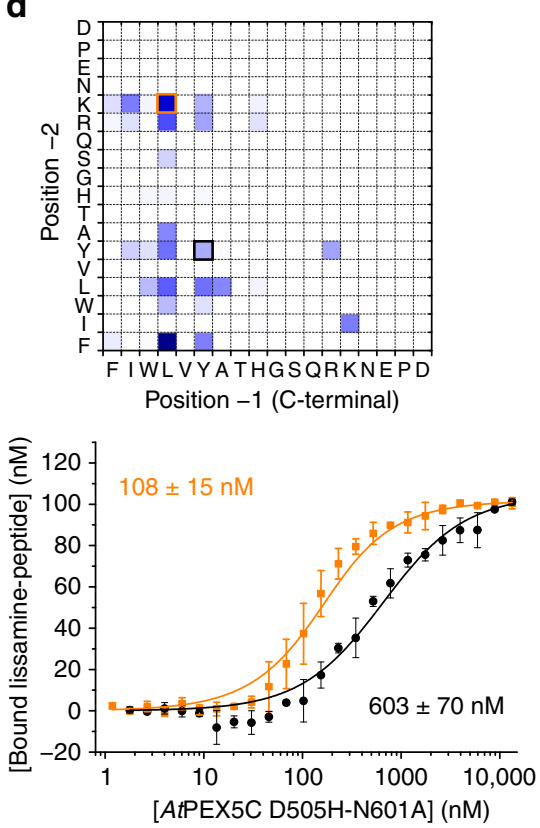

b
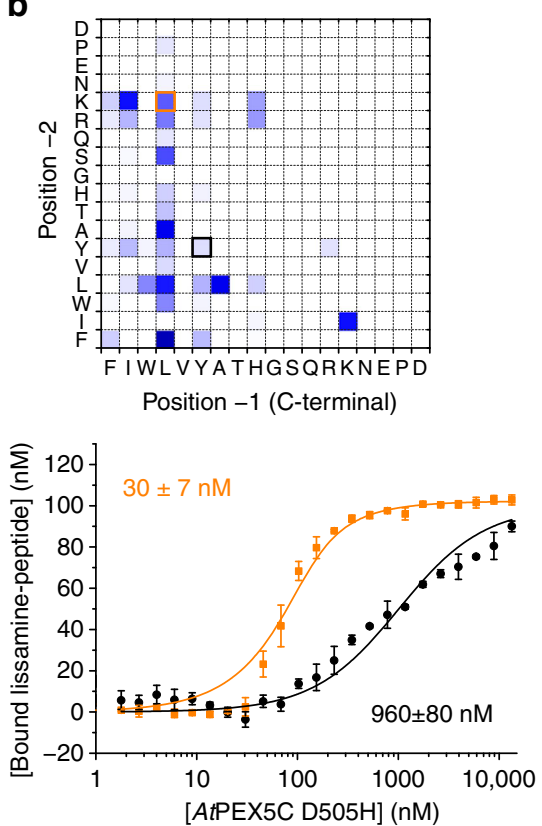

C
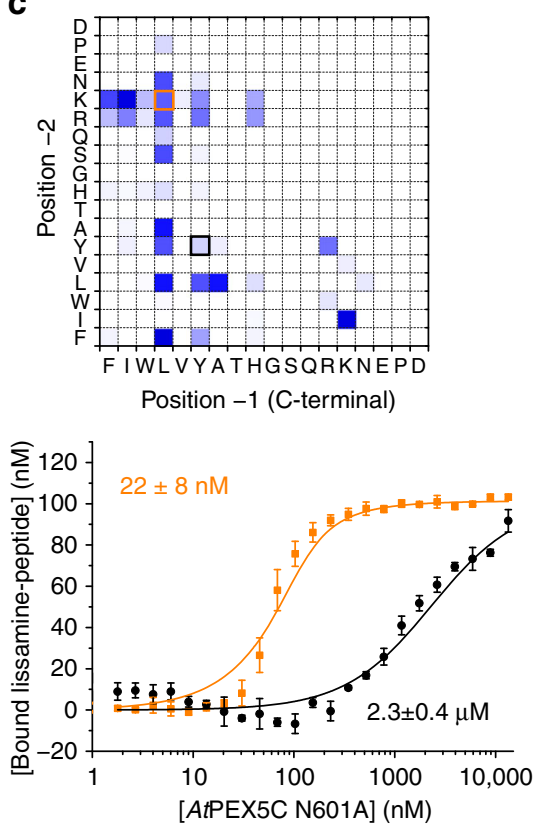

e
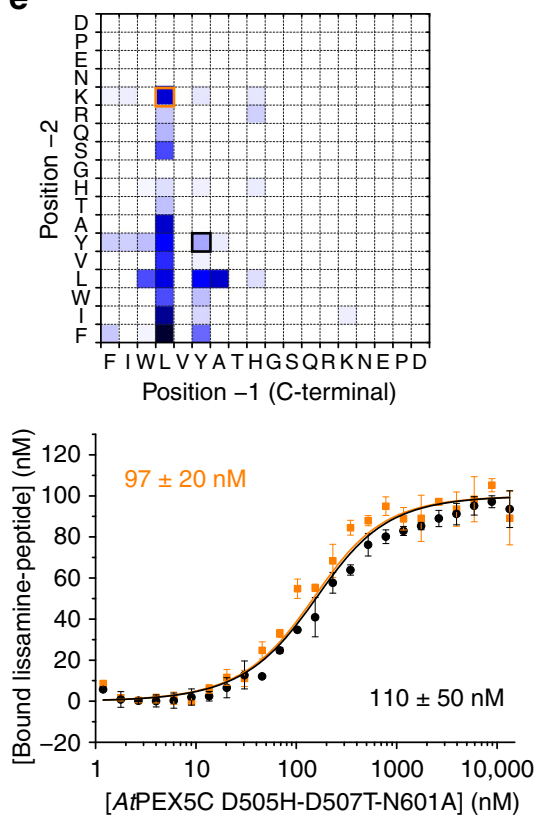

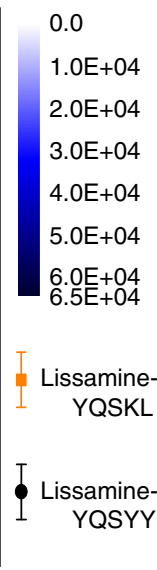

$.0 \mathrm{E}+04$

$2.0 \mathrm{E}+04$

$3.0 \mathrm{E}+04$

$4.0 \mathrm{E}+04$

$6.0 \mathrm{E}+04$

issamineQSKL

YSYY

Fig. 2 Peptide-binding selectivities for wild-type and key AtPEX5C variants. Heat maps (showing area-under-extracted ion chromatograms (EICs) for pulled-down peptides are shown, along with fluorescence anisotropy results using lissamine-YQSKL (orange) and lissamine-YQSYY (black). Darker blue indicates increased area-under-EIC in the LC-MS analysis. a Wild-type AtPEX5C. b AtPEX5C D505H. c AtPEX5C N601A. d AtPEX5C D505H-N601A. e AtPEX5C D505H-D507T-N601A. Across the series a-e, an increased affinity of protein variants to lissamine-YQSYY is observed, along with a decrease in affinity for lissamine-YQSKL. The curves represent non-linear least squares fitting to a 1:1 binding model, fitted using OriginPro. Error bars represent standard deviations of triplicate repeats

moss is an excellent model organism as it grows on a simple medium, has a fully sequenced genome that can be easily engineered through homologous recombination, is highly amenable to microscopic analysis, and is established as a bioreactor in biotechnological applications ${ }^{29-31}$. The TPR domain sequences of both the wild-type AtPEX5 receptor and the At $\mathrm{PEX}^{*}$ receptor $(\mathrm{D} 505 \mathrm{H}-\mathrm{D} 507 \mathrm{~T}-\mathrm{N} 601 \mathrm{~A})$ were combined with the N-terminus of the wild-type PhypaPEX5 sequence to create the two hybrid receptors PEX5 and PEX5*. This approach ensured that receptor docking and recycling functions, which are a property of the PEX5N-terminal domain, were not compromised as a result of any potential cross-species incompatibility. Fluorescent reporter proteins RFP and GFP were used for in vivo testing of the $\mathrm{PEX}^{\star}{ }^{*}-\mathrm{PTS}^{*}$ pair. While strong PTS1 tripeptides are both necessary and sufficient for peroxisome targeting, bioinformatics, mutational, and structural analysis all point to enhancing roles for the immediately upstream amino acids ${ }^{11-13}$. Therefore, RFP was modified to append the following: (1) the C-terminal 14 amino acids from a $P$. patens predicted peroxisomal short-chain dehydrogenase/reductase 
(Pp3c18_20320) (GETIVVAGGMKSRL; 'PTS1'), or (2) the 14 C-terminal amino acids from an inositol phosphatase (Pp3c3_21240), which is predicted to be non-peroxisomal (IIAAVDASYNSSTL; 'nonPTS1') to serve as a negative control. GFP was modified by appending the sequence YQSYY including enhancing upstream residues (WWRDPYSPMYQSYY), to form an equivalent length and predicted higher affinity $\mathrm{PTS}^{\star}{ }^{\star}$ at its C-terminus. Targeting predictions used the PredPlantPTS1 server $^{21,22}$. The genes encoding the hybrid receptors PEX5 or $\mathrm{PEX} 5^{*}$ were present on the same vector as the RFP reporter, which ensured that all cells with RFP signal also expressed the untagged receptor (Fig. 3a). This was essential, as tagging PEX5 with a bulky protein at its C-terminus blocks re-export ${ }^{32}$ and a large $\mathrm{N}$-terminal tag could potentially interfere with docking or ubiquitination.

When plasmids containing the RFP-PTS1 sequence were transiently expressed in $P$. patens cells, distinct punctate bodies were visible using fluorescence microscopy. This indicates import of RFP-PTS1 into the peroxisome (Fig. 3b). Import was functional regardless of whether the plasmid contained the PEX5 or PEX5* receptor (Fig. 3b, Supplementary Figs. 4b, 5b). The efficient import observed in the presence of $\mathrm{PEX} 5^{\star}$ can be accounted for by the endogenous PhypaPEX5, as bombardment of moss with the RFP-PTS1 gene in the absence of any additional receptor on the plasmid also results in similar peroxisomal fluorescence (Supplementary Fig. 6a). Conversely, bombardment of $P$. patens cells with GFP-PTS1* resulted in cytosolic localization of the green fluorescence, indicating that
GFP-PTS1* is not recognized by the endogenous PhypaPEX5 (Fig. 3b, Supplementary Fig. 6b).When RFP was appended with the nonPTS1 sequence, the red fluorescence was observed uniquely in the cytosol, regardless of whether PEX5 or PEX5* was present on the plasmid, showing that $\mathrm{PEX}^{*}$ did not recognize this nonPTS1 sequence.

The 'RFP \& receptor'-containing plasmid was then mixed with GFP plasmid prior to bombardment into $P$. patens cells. When the plasmid containing RFP-PTS1 and PEX5 was co-bombarded with GFP-PTS1*, red fluorescence was clearly localized in punctate peroxisomes in most cells (Supplementary Fig. 7b); however, the green fluorescence was almost completely cytosolic (Fig. 3c). In contrast, in the presence of the PEX5* receptor, distinct peroxisomal localization of GFP-PTS1* was clearly observed, while the fluorescence from RFP-PTS1 was mostly cytosolic (Supplementary Fig. 8b), demonstrating a switch in import selectivity. RFP-nonPTS1 remained cytosolic in all experiments.

To provide a quantitative analysis, the intracellular distribution of fluorescent markers was ranked on a scale of $1-5$, where 5 represented complete peroxisomal localization and 1 represented fully cytosolic localization. Each image was independently classified by at least 7 assessors and monochrome images were assessed blind without the knowledge of which plasmid combination had been used, or whether red or green channels were being viewed. More than 80 images were used to generate the final classification averages for each plasmid combination a

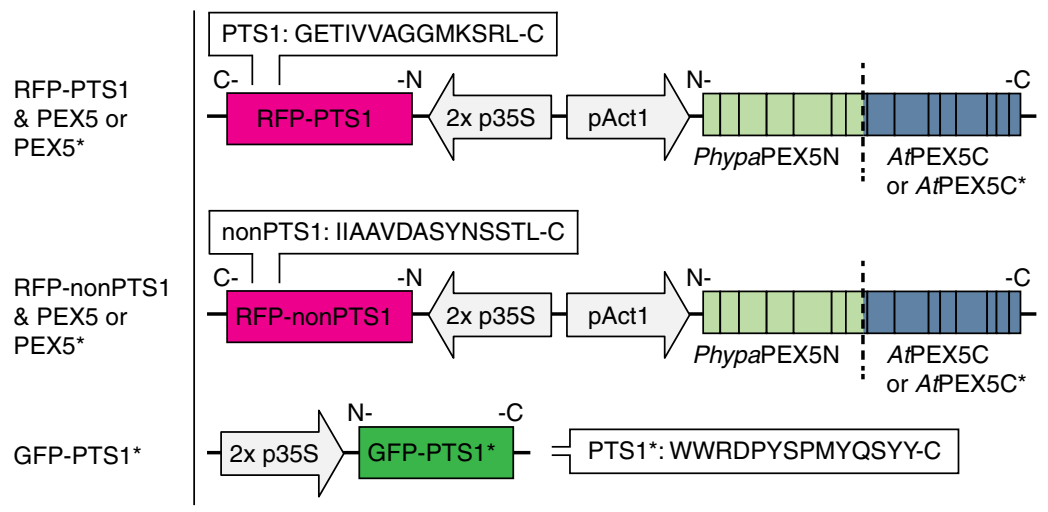

b

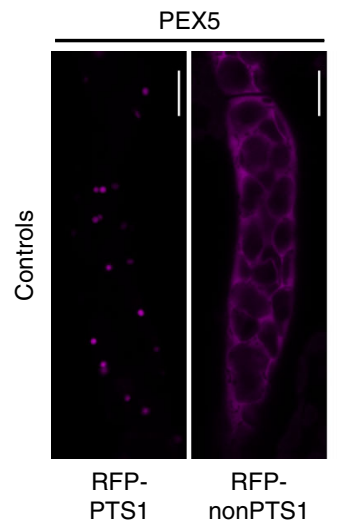

PEX5*

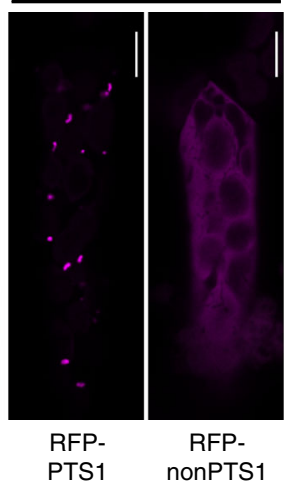

PhypaPEX5

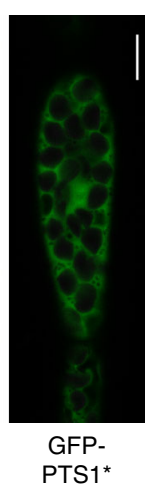

C

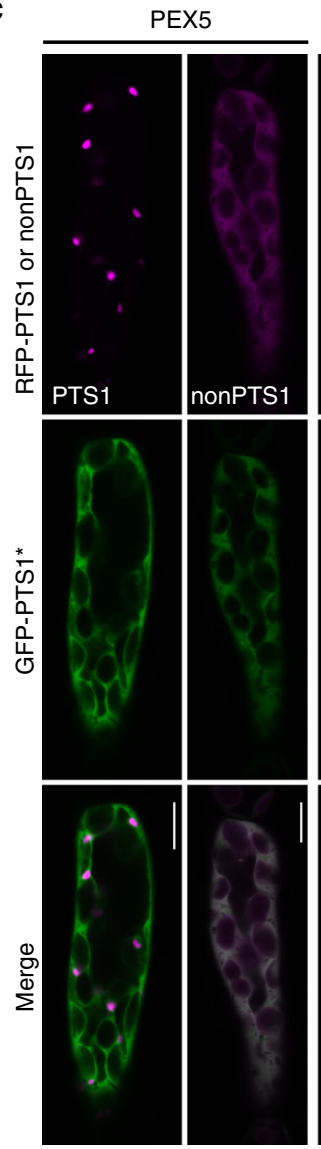

PEX5*

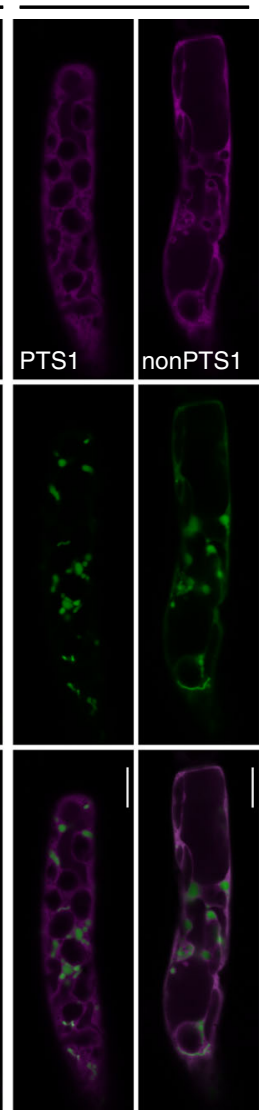

Fig. 3 In vivo transient expression. a Constructs produced for the in vivo expression in P. patens. RFP-PTS1 or nonPTS1 was on the same vector as the hybrid receptor (PhypaPEX5N-AtPEX5C (PEX5 or PEX5*)), and GFP-PTS1 ${ }^{\star}$ was on a separate vector. $\mathbf{b}, \mathbf{c} 36-48 \mathrm{~h}$ transient expression of constructs in P. patens cells. b Control experiments, expressing either RFP-PTS1 or -nonPTS1 \& receptor alone, or GFP-PTS1* alone. GFP and RFP channels (merged) are shown for these images. c Co-transformation of both vectors (shown in part $\mathbf{a}$ of the figure). PEX $5^{\star}$ imports GFP-PTS1 ${ }^{\star}$ into peroxisomes, whereas PEX5 does not (under any of the conditions tested). Scale bars, $10 \mu \mathrm{m}$ 
(Fig. 4, Supplementary Table 2). Histograms of the spread of classifications of images were also generated to compare the distribution of outcomes (Supplementary Fig. 9).

This larger analysis reinforces the qualitative observations of individual images. Experiments in the absence of GFP-PTS1 ${ }^{*}$ showed that RFP-PTS1 is imported into peroxisomes (score $>4$ ) regardless of the presence of the additional PEX5 or $P E X 5^{\star}$ gene (Fig. 4a). Similarly, expressing GFP-PTS1* alone results in no peroxisomal import (score $\sim 1$ ) in the absence of the $P E X 5^{\star}$ gene. When both plasmids are introduced, there is a clear switch in the import selectivity of cells transiently expressing the PEX5* receptor when compared to those transiently expressing the PEX5 receptor (Fig. 4a). Co-expression of PEX5 with RFP-PTS1 and GFP-PTS1* recapitulates the phenotypes observed when the
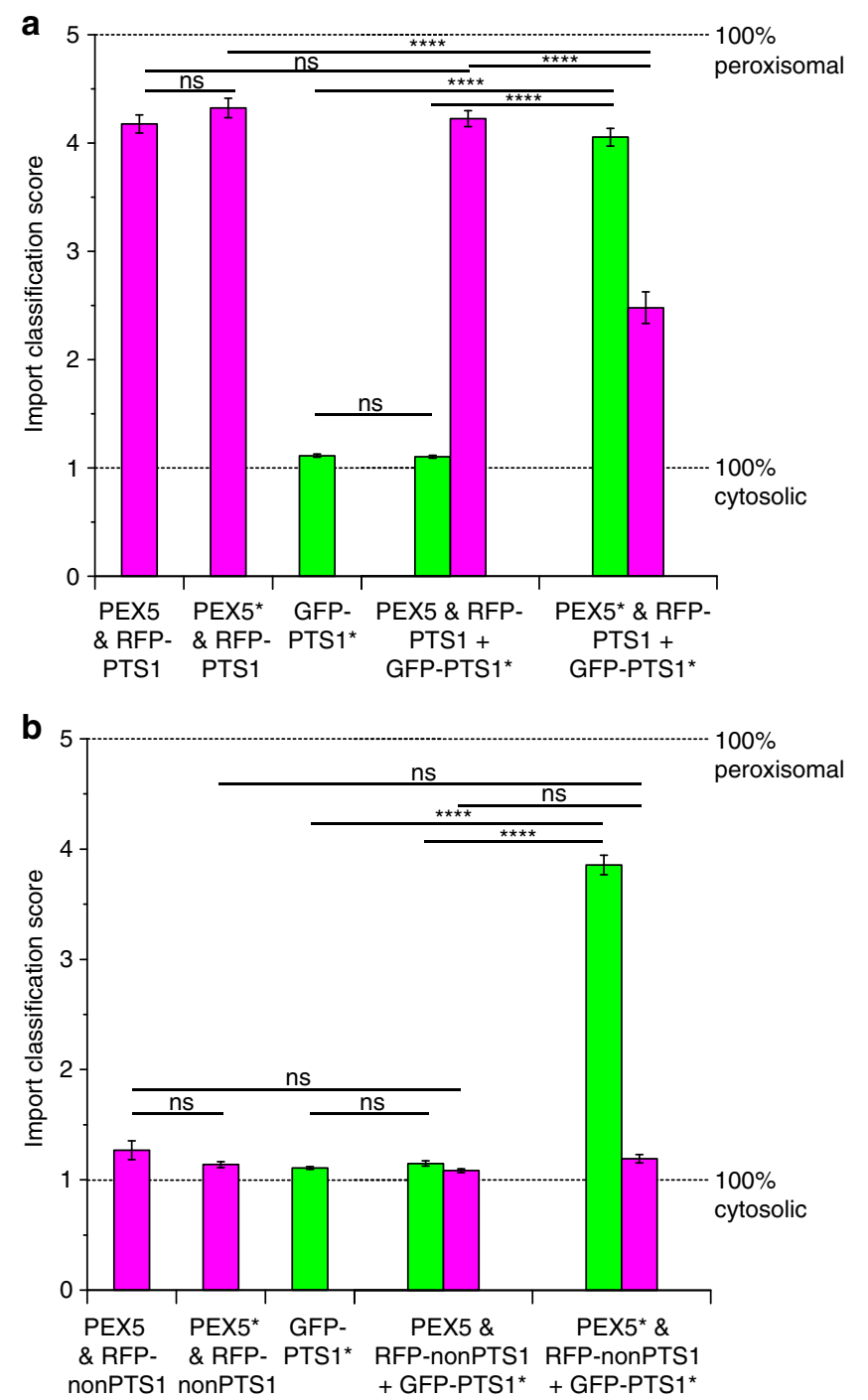

Fig. 4 Quantitative analysis of peroxisome protein import. a, b Transient expression of constructs in P. patens cells. a RFP-PTS1 \& PEX5, RFP-PTS1 \& PEX5*, b RFP-nonPTS1 \& PEX5, or RFP-nonPTS1 \& PEX5*, all with and without GFP-PTS1*. Significant peroxisomal import of GFP-PTS1* was observed when PEX $5^{\star}$ was expressed in P. patens, regardless of which RFP reporter was present. No such increase was seen in the absence of PEX5*. There was also a significant decrease in RFP-PTS1 import upon PEX $5^{\star}$ expression. Error bars represent standard errors, $n=84-115$ (Supplementary Table 2). ns not significant; ${ }^{\star \star \star \star} P<0.0001$, determined by a Kolmogorov-Smirnov test on the original histograms (Supplementary Fig. 9, Supplementary Tables 3, 4) plasmids were introduced individually (RFP-PTS1 localization $4.23 \pm 0.07$, GFP-PTS $1^{\star}$ localization $1.10 \pm 0.01$; errors represent the standard error across the images analyzed - see Supplementary Table 2 for image numbers). However, upon expression of $\mathrm{PEX}^{\star}$, cells are newly able to efficiently direct GFP-PTS1 ${ }^{\star}$ to peroxisomes (GFP-PTS $1^{\star}$ localization $4.05 \pm 0.08$ ). Interestingly, import of RFP-PTS1 was strongly reduced, though not completely cytosolic (localization $2.48 \pm 0.15$ ), but this was dependent on the co-expression of GFP-PTS1*, as PEX5* expression by itself did not affect RFP-PTS1 import (localization $4.32 \pm 0.09$ ) (Fig. 4a). These data suggest that GFP-PTS1*-loaded $\mathrm{PEX}^{\star}{ }^{*}$ outcompeted the endogenous receptor-cargo complexes for some limiting step in the import pathway. Strong import of GFP-PTS1* by PEX5* was also observed when the non-competitive cargo RFP-nonPTS1 was co-expressed (localization $3.86 \pm 0.09$ ) (Fig. 4b).

Confirmation that GFP-PTS1* was indeed delivered to the peroxisome (rather than an alternative compartment) by $\mathrm{PEX}^{\star}$ was obtained by careful analysis of images in which partial import of RFP-PTS1 is also seen. Clear co-localization of red and green fluorescence is observed in the punctate structures, which is strongly indicative of a peroxisomal localization (Supplementary Figs. 8b, 10d). We recently reported that genetic knockout of $P E X 11$, a gene involved in peroxisome division, in $P$. patens leads to the formation of giant peroxisomes ${ }^{33}$. Additional evidence for peroxisomal localization of the fluorophores was obtained using this mutant line. Bombardment of the pex11ko line with the plasmids containing GFP-PTS1*, RFP-PTS1 and PEX5 led to the localization of red fluorescence in large peroxisomes, while the GFP remained cytosolic. When the fluorescent reporters were expressed in the presence of PEX5*, the selectivity was switched so that the large peroxisomes selectively imported the GFP, with some cases of co-localization with RFP (Supplementary Fig. 10a-c).

\section{Discussion}

Manipulation of the substrate specificity of enzymes, often by directed evolution, is well established for both catalysis and the understanding of metabolic pathways (such as kinase engineering to accept ATP analogues) ${ }^{34-37}$. However, the modification of protein-protein interactions is far less reported ${ }^{38-41}$. Here we have demonstrated the engineering of a protein-protein interaction that can support functional peroxisomal protein trafficking in vivo. Native peroxisomal protein import is characterized by the high plasticity of the PEX5 receptor, which can accommodate a number of different natural PTS1 sequences. This sequence tolerance was a complicating factor in the search for a novel targeting signal-receptor pair. We built on previous work showing good correlation between the strength of binding of signal peptides and import efficiency ${ }^{17}$ to demonstrate that an approach of selecting mutations and screening libraries of peptides using LC-MS can quickly identify those sequences with the greatest potential to act as orthogonal motifs. Iterative development led to the variant AtPEX5C ${ }^{\star}$, which showed high affinity in vitro for the pentapeptide YQSYY (which bound only weakly to wild-type AtPEX5C). AtPEX5C* also showed a significantly decreased affinity for a prototypical PTS1 pentapeptide. Bioinformatic tools guided further optimization of upstream residues, enhancing the predicted ability of the orthogonal targeting signal $\left(\mathrm{PTS}^{\star}{ }^{\star}\right)$ to promote cargo import in vivo in moss cells. Transient expression of fluorescent reporter proteins tagged with PTS1 or PTS1* sequences and their cognate receptors enabled the intracellular distribution of cargo proteins to be visualized.

The high affinity of $\mathrm{PEX}^{*}$ for the $\mathrm{PTS} 1^{\star}$ sequence resulted in preferential import of $\mathrm{PTS} 1^{\star}$-tagged proteins at the expense of 
native PTS1 sequences, even when the cell was still expressing endogenous PhypaPEX5, with the PEX5 ${ }^{\star}-\mathrm{PTS1}^{*}$ pairing outcompeting the endogenous pathway. Interestingly, this competition only occurred in the presence of the $\mathrm{PTS}^{*}$ cargo, suggesting that there is selection for cargo-loaded receptor at the peroxisomal membrane. PEX5 insertion into purified rat liver peroxisomes was shown to be cargo-dependent by Gouveia and colleagues $^{42}$, although recombinant cargo-free PEX5 can bind its purified docking partner PEX14 in vitro ${ }^{16}$. It will be interesting to explore the mechanistic basis of this selectivity.

The ability of the PEX5*-PTS1* pair to outcompete import of endogenous PTS1 proteins provides a convenient tool to manipulate peroxisomal protein import in vivo, thereby allowing measurement of rates of import and half-life of cytosolic and peroxisomal proteins - parameters which are useful for modelling in vivo peroxisome protein trafficking, and in systems biology. Our results also suggest that this mutated receptor and targeting signal pairing can be used to drive a switch in peroxisomal function, allowing import of user-specified proteins without competition from endogenous proteins. This switch in peroxisomal function could bring about a repurposing of the peroxisome within the cell for use as a novel intracellular compartment. While creating a true designer organelle that exists in parallel with naturally occurring compartments (including the peroxisome) will require manipulation of several other aspects of organelle biogenesis, this work demonstrates the creation of a new and orthogonal trafficking pathway, an essential component for the realization of this goal in synthetic biology.

\section{Methods}

DNA and protein sequences of key constructs used in this study are shown in Supplementary Figs. 11-24.

Site-directed mutagenesis of AtPEX5C. The gene encoding $\mathrm{His}_{6}$-AtPEX5 (340-728), referred to as AtPEX5C, contained within the pET-28b vector, is described by Lanyon-Hogg and colleagues ${ }^{16}$. Mutations were introduced using a QuikChange Lightning site-directed mutagenesis kit (Agilent Technologies) according to manufacturer's instructions. Transformation of each DpnI-treated mutagenesis reaction into XL10-Gold cells was performed, followed by DNA purification and confirmation of mutagenesis by sequencing (Beckman Genomics).

\section{Expression and purification of AtPEX5C and variants. The AtPEX5C DNA} (wild-type or mutant) was transformed into E. coli BL21-Gold (DE3) cells for efficient protein expression. Overnight growth of single colonies in $5 \mathrm{ml}$ selection medium (Lysogeny broth containing kanamycin at $50 \mathrm{mg} \mathrm{l}^{-1}$ ) at $37^{\circ} \mathrm{C}$ was performed, followed by inoculation of $20 \mu \mathrm{l}$ of this culture into $1 \mathrm{ml}$ selection media at $37^{\circ} \mathrm{C}$, and growth for $8 \mathrm{~h}$ ('day culture'). Autoinduction medium (tryptone $(1 \% \mathrm{w} / \mathrm{v})$, yeast extract $(0.5 \% \mathrm{w} / \mathrm{v}), \mathrm{NaOH}(1 \mathrm{mM}),\left(\mathrm{NH}_{4}\right)_{2} \mathrm{SO}_{4}(25 \mathrm{mM})$, $\mathrm{KH}_{2} \mathrm{PO}_{4}(50 \mathrm{mM}), \mathrm{Na}_{2} \mathrm{HPO}_{4}(50 \mathrm{mM}), \mathrm{MgSO}_{4}(1 \mathrm{mM})$, glycerol $(0.5 \% \mathrm{w} / \mathrm{v})$, glucose $(0.05 \% \mathrm{w} / \mathrm{v}), \alpha$-lactose $(0.2 \% \mathrm{w} / \mathrm{v})$, kanamycin $\left.\left(100 \mathrm{mg} \mathrm{l}^{-1}\right)\right)$ was inoculated with day culture $(250 \mu \mathrm{l}$ into $500 \mathrm{ml}$ of autoinduction medium) and incubated at $28^{\circ} \mathrm{C}$ for $18 \mathrm{~h}$. Cells were collected by centrifugation and resuspended in wash buffer $\left(\mathrm{Na}_{2} \mathrm{HPO}_{4}(50 \mathrm{mM}), \mathrm{NaCl}(300 \mathrm{mM}), 2\right.$-mercaptoethanol $(10 \mathrm{mM})$, glycerol $(15 \% \mathrm{v} / \mathrm{v}), \mathrm{pH} 8.0$ with $1 \mathrm{M} \mathrm{NaOH}), 40 \mathrm{ml}$ per $500 \mathrm{ml}$ original autoinduction culture). Protein purification was performed following cell lysis by two passes at 30 kpsi through a cell disruptor (Constant Systems, TS Series Benchtop Cell Disruptor). The supernatant of the lysed cells was incubated with Co-NTA resin (Thermo Scientific, $500 \mu \mathrm{l}$ settled resin per $40 \mathrm{ml}$ supernatant) at $4{ }^{\circ} \mathrm{C}$, for $1 \mathrm{~h}$, with agitation. The supernatant was removed, the resin was washed with wash buffer $(4 \times 15 \mathrm{ml}$ washes) and the protein eluted from the Co-NTA resin with elution buffer (wash buffer containing $100 \mathrm{mM}$ imidazole, $2 \mathrm{ml}$ per $500 \mathrm{ml}$ original autoinduction culture). The resulting protein identity and purity was confirmed using SDS-PAGE and ESI-LC-MS (Supplementary Fig. 25).

Lissamine-labelled peptide synthesis. Lissamine sulfonyl chloride-labelled peptides were prepared using Fmoc solid-phase peptide synthesis: $100 \mathrm{mg}$ of leucine- or tyrosine-loaded 2-chlorotrityl chloride resin (Merck) was added to a fritted reaction vessel. The resin was swelled in dimethylformamide (DMF; $5 \mathrm{ml}$ ) for $1 \mathrm{~h}$, and then the reaction vessel was drained. DMF washes were performed $(3 \times 2 \mathrm{ml} \times 2 \mathrm{~min})$, followed by washes with $20 \%$ piperidine in DMF $(5 \times 2 \mathrm{ml} \times 2 \mathrm{~min})$, and DMF $(5 \times 2 \mathrm{ml} \times 2 \mathrm{~min})$. FmocBoc Lys or Fmoc ${ }^{\mathrm{B} u ~ T y r}$ (5 e.q.) in DMF $(1 \mathrm{ml})$ was added, along with $O$ - $(1 H$-6-chlorobenzotriazole-1-yl)- 1,1,3,3-tetramethyluronium hexafluorophosphate (HCTU; 5 e.q.) in DMF (1 ml) and diisopropylethylamine (DIPEA; 10 e.q.). The reaction was agitated for $1 \mathrm{~h}$ at RT then washed with DMF, deprotected (20\% piperidine in DMF) and washed (DMF). The remaining couplings, of the $\mathrm{S}, \mathrm{Q}$, and $\mathrm{Y}$ residues, were performed using similar procedures. The N-terminal position was capped by coupling with lissamine rhodamine B sulfonyl chloride (Thermo Fisher Molecular Probes). Lissamine ( 3 e.q.) was added to the resin-bound peptide $\left(1\right.$ e.q.) at $0{ }^{\circ} \mathrm{C}$, and anhydrous DIPEA (10 e.q.) was added before stirring the solution overnight in the absence of light. The solution was filtered from the resin, which was then washed with DMF $(3 \times 2 \mathrm{ml})$, dichloromethane $(\mathrm{DCM})(3 \times 2 \mathrm{ml})$, and $\mathrm{MeOH}(3 \times 2 \mathrm{ml})$ and dried under reduced pressure. The peptides were cleaved from the solid resin support using a cleavage cocktail of trifluoroacetic acid (TFA), $\mathrm{H}_{2} \mathrm{O}$, and triisopropylsilane (95:2.5:2.5), which was added to dried resin $(500 \mu \mathrm{l}$ per $25 \mathrm{mg}$ resin) and agitated for $1 \mathrm{~h}$ at RT. The cleavage mixture was filtered drop-wise into cold diethyl ether (1:100) and precipitated peptide was collected by centrifugation. Three diethyl ether washes were performed. The combined diethyl ether layers were extracted with water and the aqueous layer combined with the precipitated peptide, lyophilized and purified by reverse phase HPLC.

Peptide library synthesis. The peptide libraries were prepared using Fmoc solid-phase peptide synthesis using a split and pool approach. Side-chain protecting groups were $(\mathrm{S}, \mathrm{T}, \mathrm{Y}) \mathrm{:}^{\mathrm{t}} \mathrm{Bu},(\mathrm{D}, \mathrm{E}): \mathrm{O}^{t} \mathrm{Bu},(\mathrm{H}, \mathrm{N}, \mathrm{Q}): \mathrm{Trt},(\mathrm{W}, \mathrm{K}): \mathrm{Boc}, \mathrm{R}: \mathrm{Pbf}$. Four sub-libraries were prepared to enable deconvolution of isobaric peptides. The sub-libraries were combined for the pull-down assays. The four sub-libraries had the following sequences:

Sub-library 1:

dansyl-[Y]-[Q]-[S]-[D/F/G/H/I/K/N/P/S/V]-[D/F/G/H/I/K/N/P/S/V]- $\mathrm{CO}_{2} \mathrm{H}$ Sub-library 2:

dansyl-[Y]-[Q]-[S]-[D/F/G/H/I/K/N/P/S/V]-[A/E/L/M/Q/R/T/W/Y]-CO ${ }_{2} \mathrm{H}$ Sub-library 3:

dansyl-[Y]-[Q]-[S]-[A/E/L/M/Q/R/T/W/Y]-[D/F/G/H/I/K/N/P/S/V]-CO ${ }_{2} \mathrm{H}$

Sub-library 4:

dansyl-[Y]-[Q]-[S]-[A/E/L/M/Q/R/T/W/Y]-[A/E/L/M/Q/R/T/W/Y]- $\mathrm{CO}_{2} \mathrm{H}$

Peptide sub-libraries were synthesized by first adding $30 \mathrm{mg}$ of each of the required preloaded 2-chlorotrityl chloride resin (Merck) bearing the required -1 residues into a fritted reaction vessel. The pooled resin was swelled in DMF $(5 \mathrm{ml})$ for $1 \mathrm{~h}$, and then the reaction vessel was drained. DMF washes were performed $(3 \times 2 \mathrm{ml} \times 2 \mathrm{~min})$, followed by washes with $20 \%$ piperidine in DMF $(5 \times 2 \mathrm{ml} \times$ $2 \mathrm{~min})$, and DMF $(5 \times 2 \mathrm{ml} \times 2 \mathrm{~min})$. Resin was washed with $\mathrm{DCM}(3 \times 2 \mathrm{ml} \times$ $2 \mathrm{~min}$ ) and dried in vacuo before mixing thoroughly and splitting equally between reaction vessels for coupling of each of the amino acids at position -2 . To each aliquot of resin, a different Fmoc-protected amino acid (5 e.q.) in DMF (1 ml) was added along with HCTU (5 e.q.) in DMF $(1 \mathrm{ml})$ and DIPEA (10 e.q.). The reaction was agitated for $1 \mathrm{~h}$ at RT. Following washing with DMF, all aliquots of resin were pooled for the deprotection (20\% piperidine in DMF) and wash (DMF) steps. The remaining couplings, of the $\mathrm{S}, \mathrm{Q}$, and $\mathrm{Y}$ residues, were performed on the pooled resin using similar procedures. The $\mathrm{N}$-terminal position was capped by coupling with dansyl chloride (Sigma-Alrich). The resin-bound peptide library (1 e.q.) was swelled in DMF $(2 \mathrm{ml})$ for $1 \mathrm{~h}$. DMF was drained from the reaction vessel. DIPEA (6 e.q.) was added to dansyl chloride ( 5 e.q.) in DMF $(2 \mathrm{ml})$, and the solution was well mixed, incubated at RT for $10 \mathrm{~min}$, then added to the resin-bound peptide library (1 e.q.) and stirred overnight. The solution was filtered from the resin, which was then washed with DMF $(3 \times 2 \mathrm{ml})$, DCM $(3 \times 2 \mathrm{ml})$ and $\mathrm{MeOH}$ $(3 \times 2 \mathrm{ml})$, and dried under reduced pressure. The peptides were cleaved from the solid resin support using a cleavage cocktail of TFA, $\mathrm{H}_{2} \mathrm{O}$, and triisopropylsilane (95:2.5:2.5), which was added to dried resin $(500 \mu \mathrm{l}$ per $25 \mathrm{mg}$ resin) and agitated for $1 \mathrm{~h}$ at RT. The cleavage mixture was filtered drop-wise into cold diethyl ether (1:100) and precipitated peptide was collected by centrifugation. Three diethyl ether washes were performed. The combined diethyl ether layers were extracted with water and the aqueous layer combined with the precipitated peptide, lyophilized and re-suspended in sterile water to the desired concentration.

Pull down of binding peptides by AtPEX5C protein. Purified protein (final concentration: $12.5 \mu \mathrm{M}$ ) was added to the combined peptide library (final concentration: $500 \mathrm{nM}$ each peptide in the library (concentration calculated based on the average molecular weight of the peptides in each sub-library)) in a $500 \mu \mathrm{l}$ reaction mixture in wash buffer $\left(\mathrm{Na}_{2} \mathrm{HPO}_{4}(50 \mathrm{mM}), \mathrm{NaCl}(300 \mathrm{mM}), 2\right.$ mercaptoethanol $(10 \mathrm{mM})$, glycerol $(15 \% \mathrm{v} / \mathrm{v}), \mathrm{pH} 8.0$ with $1 \mathrm{M} \mathrm{NaOH})$, and incubated at $4{ }^{\circ} \mathrm{C}$ for $1 \mathrm{~h}$ with agitation. This protein-peptide mixture was added to Co-NTA resin $(100 \mu \mathrm{l}$ settled resin per $500 \mu \mathrm{l}$ reaction) and this was incubated at $4{ }^{\circ} \mathrm{C}$ for $1 \mathrm{~h}$ with agitation. Supernatant was removed and $500 \mu \mathrm{l}$ wash buffer was added to the resin $(4 \times 500 \mu \mathrm{l}$ washes), followed by wash buffer containing $5 \mathrm{mM}$ imidazole $(3 \times 500 \mu$ l washes). Remaining bound peptides were effectively eluted from the protein by incubating the resin with wash buffer containing $6 \mathrm{M}$ urea $(300 \mu \mathrm{l})$ at $4{ }^{\circ} \mathrm{C}$ for $30 \mathrm{~min}$ with agitation, to unfold the protein. Eluate was collected in tapered vials and $10 \mu \mathrm{l}$ was injected for analysis by ESI-LC-MS.

LC-MS analysis of peptides. Electrospray ionization LC-MS was performed using a Bruker MaXis Impact time-of-flight mass spectrometer in the positive ion mode. 
Analytical column used: Waters Acquity UPLC Peptide CSH C18 column $130 \AA$, $1.7 \mu \mathrm{m}$ stationary phase (column dimensions $2.1 \times 100 \mathrm{~mm}$ ) fitted with the corresponding Vanguard pre-column guard (guard column dimensions $2.1 \times 5 \mathrm{~mm}$ ). UPLC was performed using a Dionex Ultimate 3000 HPLC, with the following solvents: (A) water $+0.1 \%$ formic acid; (B) acetonitrile $+0.1 \%$ formic acid. Gradient timetable (flowrate $0.7 \mathrm{ml} \mathrm{min}^{-1}$, linear gradients between points): $-1.3 \mathrm{~min}$ $=99: 1 \mathrm{~A}: \mathrm{B}$ (pre-equilibration); $0 \mathrm{~min}=$ inject; $0.3 \mathrm{~min}=99: 1 \mathrm{~A}: \mathrm{B} ; 1.5 \mathrm{~min}=80: 20$ $\mathrm{A}: \mathrm{B} ; 2.5 \min =78: 22 \mathrm{~A}: \mathrm{B} ; 4.5 \min =70: 30 \mathrm{~A}: \mathrm{B} ; 5.5 \min =60: 40 \mathrm{~A}: \mathrm{B} ; 6 \min =5: 95$ $\mathrm{A}: \mathrm{B} ; 7.5 \mathrm{~min}=1: 99 \mathrm{~A}: \mathrm{B}$. Calibration of the mass spectrometry instrument was performed using sodium formate, injected at the end of each run. The following analysis steps were automated using the VBScript functions within the Bruker DataAnalysis software, or using custom VBA routines in Microsoft Excel.

Generation of extracted ion chromatograms. Following acquisition of the data, an extracted ion chromatogram was generated for ions corresponding to each of the unique formulas contained within the peptide library. $(\mathrm{M}+\mathrm{H})^{+}$ions were considered for all peptides, and $(\mathrm{M}+2 \mathrm{H})^{2+}$ peptides were also considered for peptides containing $\mathrm{R}$ and $\mathrm{K}$ residues. The extracted ion chromatograms were created with a width of $\pm 0.008 \mathrm{Da}$. The chromatograms were smoothed and integrated, and the retention times and areas were used in subsequent analysis.

Generation of reference retention times for peptides. Each peptide sub-library was analyzed using the LC-MS method listed above and an identical chromatographic run in which the mass spectrometer provided automated MS/MS data, using collisional induced fragmentation in the quadrupole. Based on the original composition of the library, the accurate mass of each of the peptides (represented by the appearance of a peak in the extracted ion chromatograms) and the observation of the $y_{1}$ fragment ions, unique retention times could be determined for the vast majority of peptides within the mixture. Where no chromatographic separation was observed, the retention time was associated with both sequences. The full reference data set is available in Supplementary Data 1 and 2.

Identification of peptides from pull-down experiments. The extracted ion chromatogram data were compared with the reference mass-retention time list to identify the best match between the data observed and the reference set. A small retention time drift of up to $\pm 5 \mathrm{~s}$ was allowed in this matching process, and the best match was determined by whichever offset gave the lowest minimal RMS deviation of retention times between sets. Typically retention time offsets were $\leq 1 \mathrm{~s}$. Once identified, the EIC areas were plotted against the peptide sequences in heat map plots using OriginPro.

Fluorescence anisotropy. FA assays used an Envision ${ }^{\mathrm{TM}} 2103$ multilabel plate reader (Perkin Elmer) and were performed in 384-well microtiter plates (Black Perkin Elmer Optiplates) as follows. Four solutions were prepared (A: FA buffer (HEPES (20 mM), $\mathrm{NaCl}(150 \mathrm{mM}), \mathrm{pH} 7.5)$; B: Blocking solution: FA buffer containing $0.32 \mathrm{mg} \mathrm{ml}^{-1}$ of porcine gelatine; C: $40 \mu \mathrm{M}$ solution of AtPEX5C or variant in FA buffer; D: Fluorescent tracer solution: $200 \mathrm{nM}$ solution of lissamineYQSKL or lissamine-YQSYY in FA buffer). A total of $80 \mu \mathrm{l}$ of solution B was added to all wells and the plate sealed and incubated at $4{ }^{\circ} \mathrm{C}$ overnight. A volume of $60 \mu \mathrm{l}$ of solution B was removed from each well and $40 \mu \mathrm{l}$ of solution C was added to wells in column 1 of the plate, followed by agitation and transfer of $40 \mu \mathrm{l}$ to the corresponding wells in column 2 . This process was repeated up to column $23(40 \mu \mathrm{l}$ was discarded from column 23 wells after agitation, leaving column 24 with no protein solution). Finally, solution D ( $20 \mu \mathrm{l}$ per well) was then added to 3 rows and FA buffer added to the other three rows to act as blanks. The plate was incubated at $25^{\circ} \mathrm{C}$ with linear shaking for $20 \mathrm{~min}$ and then read using a Perkin Elmer Envision Plate reader using the following optics: Excitation filter $531 \mathrm{~nm}(25 \mathrm{~nm}$ bandwidth), $555 \mathrm{~nm}$ polarized dichroic mirror; emission was detected in two separate channels each with 595 (60) nm filters but with orthogonal polarization ( $\mathrm{S}$ and $\mathrm{P}$ polarizers). Thirty flashes were used per measurement. The data were blank-corrected and processed to give a blank-corrected anisotropy using Eq. (1).

$$
r=1000 \times \frac{s-g p}{s+g 2 p}
$$

where $s$ and $p$ are the blank-corrected intensities in the $s$ and $p$ polarised channels and the instrument response factor $(g)$ was set to 1.16 on the instrument.

The anisotropy was converted to the amount of tracer bound $\left(L_{\mathrm{B}}\right)$ using Eq. (2).

$$
\frac{L_{\mathrm{B}}}{L_{\mathrm{T}}}=\left[\frac{\lambda\left(r_{\max }-r\right)}{\left(r-r_{\min }\right)}+1\right]^{-1}
$$

where $L_{\mathrm{B}}$ is the concentration of fluorescent tracer bound to PEX5, $L_{\mathrm{T}}$ is the total tracer concentration $(100 \mathrm{nM}), r_{\max }$ is the maximum anisotropy and $r_{\min }$ the minimum anisotropy observed in the titration. $\lambda$ reflects the difference in quantum yields of the bound and free states, which was determined to be 1 .

The $K_{\mathrm{d}}$ for the tracer was then determined by plotting the bound tracer concentration against the total protein concentration and fitting to Eq. (3) using non-linear least squares in OriginPro. The error in $K_{\mathrm{d}}$ is obtained from the fitting error within the procedure.

$$
L_{\mathrm{B}}=\frac{\left(L_{\mathrm{T}}+P_{\mathrm{T}}+K_{\mathrm{d}}\right)-\sqrt{\left(L_{\mathrm{T}}+P_{\mathrm{T}}+K_{\mathrm{d}}\right)^{2}-4 L_{\mathrm{T}} P_{\mathrm{T}}}}{2}
$$

where $L_{\mathrm{B}}$ is the concentration of fluorescent tracer bound to PEX5, and $L_{\mathrm{T}}$ is the total tracer concentration. $P_{\mathrm{T}}$ is the total concentration of PEX5.

Moss growth and transient expression. Protonemal tissue of Physcomitrella patens (Gransden strain) was subcultured in BCDAT growth media ${ }^{43}$ containing $0.6 \%$ plant agar, and 5- to 6-day-old tissue was used to perform particle bombardment for transient expression. Plasmid DNA $0.7-1 \mu \mathrm{g}$ was coated onto tungsten M17 particles and bombarded into the moss tissue at 900 psi. Moss tissue was grown under continuous illumination (ca. $50-55 \mu \mathrm{mol} \mathrm{m}^{-2} \mathrm{~s}^{-1}$ ) at $25^{\circ} \mathrm{C}$, and imaging was conducted $36-48 \mathrm{~h}$ following bombardment.

Microscopy. Images for classification were generated using fluorescence microscopy with a Zeiss Axiolmager M2 microscope, containing Nomarski optics and a HXP120C light source. GFP and RFP were detected using Zeiss filters with Semrock narrow-band pass filters. Images were then captured with an Axiocam MRM camera through the ZEN2 software.

For confocal microscopy, a Zeiss LSM 800 laser-scanning inverted microscope with a $63 \times$ oil immersion objective was used. GFP and RFP were excited with a $488 \mathrm{~nm}$ argon laser and a $543 \mathrm{~nm}$ laser, respectively. Emissions for GFP/RFP were detected by a $488 / 543 \mathrm{~nm}$ dichroic mirror and $505-530 \mathrm{~nm} / 560-605 \mathrm{~nm}$ band pass filters. Images were generated through the ZEN2011 software and processed by Adobe Photoshop CS6 or ImageJ 1.50b.

Classification analysis. For classification, separate grayscale images of RFP and GFP channels were saved in JPEG format. Files and associated metadata (channel and experimental conditions) were uploaded to a custom webserver, which enabled the user to view an image selected at random, and classify the phenotype observed by pressing the corresponding button on the webpage. During classification, users were unaware of any metadata (i.e., which channel or experiment was being observed). Users could classify the localization of fluorescence in each image on a scale of $1-5$, where a score of $1=$ fully cytosolic, $2=\sim 75 \%$ cytosolic, $3=$ mixed, $4=\sim 75 \%$ peroxisomal and $5=$ fully peroxisomal. Where more than one cell was present in an image, the cell closest to the center was classified. Classifiers could also log the absence of fluorescence or the ambiguity in which cell was to be classified. The results of each classification by each user were logged in a database for subsequent analysis.

Data processing. The classification data were processed as follows. (1) The spread of classifications for each image were collated in Microsoft Excel. (2) Any images where more than two classifiers had indicated ambiguity (in which cell was to be classified) were removed from the data set. (3) The standard deviation of the classifications for each channel was examined. (4) Any image with a standard deviation of classification $>1.1$ was examined - single outlier classifications from erroneous clicks during classification were removed. (5) Images with bimodal distributions were removed from the analysis completely. Following application of this processing, any image with $<5$ classifications was removed from the analysis. The application of these filters resulted in loss of only 5\% of the total images used within the final classifications. Following the filtering of the data, the mean classification value for each channel for each image was determined and then the average of the mean classification for each channel across all images for each experimental condition was calculated along with the standard errors which are reported in Fig. 4. Statistical significance of the differences was determined using a Kolmogorov-Smirnov test on the original histograms showing normalized distribution of peroxisomal localization scores (Supplementary Fig. 9, Supplementary Tables 3, 4). The classification details for each image are provided in Supplementary Data 3.

Data availability. The data sets generated and/or analyzed during the current study are available in the Research Data Leeds Repository, https://doi.org/10.5518/ 218; any other data are available from the authors upon reasonable request.

Received: 28 February 2017 Accepted: 3 July 2017

Published online: 06 September 2017

\section{References}

1. Kessel-Vigelius, S. K. et al. An engineered plant peroxisome and its application in biotechnology. Plant Sci. 210, 232-240 (2013).

2. Hu, J. et al. Plant peroxisomes: biogenesis and function. Plant Cell. 24, 2279-2303 (2012). 
3. Poirier, Y., Erard, N. \& MacDonald-Comber Petetot, J. Synthesis of polyhydroxyalkanoate in the peroxisome of Pichia pastoris. FEMS Microbiol. Lett. 207, 97-102 (2002).

4. Bhataya, A., Schmidt-Dannert, C. \& Lee, P. C. Metabolic engineering of Pichia pastoris X-33 for lycopene production. Process Biochem. 44, 1095-1102 (2009).

5. DeLoache, W. C., Russ, Z. N. \& Dueber, J. E. Towards repurposing the yeast peroxisome for compartmentalizing heterologous metabolic pathways. Nat. Commun. 7, 11152 (2016).

6. Zhou, Y. J. et al. Harnessing yeast peroxisomes for biosynthesis of fatty-acidderived biofuels and chemicals with relieved side-pathway competition. J. Am. Chem. Soc. 138, 15368 (2016)

7. Meinecke, M. et al. The peroxisomal importomer constitutes a large and highly dynamic pore. Nat. Cell. Biol. 12, 273-277 (2010).

8. Meinecke, M., Bartsch, P. \& Wagner, R. Peroxisomal protein import pores Biochim. Biophys. Acta 1863, 821-827 (2016).

9. Cross, L. L., Ebeed, H. T. \& Baker, A. Peroxisome biogenesis, protein targeting mechanisms and PEX gene functions in plants. Biochim. Biophys. Acta 1863, 850-862 (2016).

10. Francisco, T. et al. Ubiquitin in the peroxisomal protein import pathway. Biochimie 98, 29-35 (2014).

11. Brocard, C. \& Hartig, A. Peroxisome targeting signal 1: is it really a simple tripeptide? BBA - Mol. Cell Res. 1763, 1565-1573 (2006).

12. Fodor, K., Wolf, J., Erdmann, R., Schliebs, W. \& Wilmanns, M. Molecular requirements for peroxisomal targeting of alanine-glyoxylate aminotransferase as an essential determinant in primary hyperoxaluria type 1. PLoS Biol. 10, e1001309 (2012)

13. Hagen, S. et al. Structural insights into cargo recognition by the yeast PTS1 receptor. J. Biol. Chem. 290, 26610-26626 (2015).

14. Gatto, G. J., Geisbrecht, B. V., Gould, S. J. \& Berg, J. M. Peroxisomal targeting signal-1 recognition by the TPR domains of human PEX5. Nat. Struct. Biol. 7, 1091-1095 (2000).

15. Carvalho, A. F. et al. The N-terminal half of the peroxisomal cycling receptor Pex5p is a natively unfolded domain. J. Mol. Biol. 356, 864-875 (2006).

16. Lanyon-Hogg, T., Hooper, J., Gunn, S., Warriner, S. L. \& Baker, A. PEX14 binding to Arabidopsis PEX5 has differential effects on PTS1 and PTS2 cargo occupancy of the receptor. FEBS Lett. 588, 2223-2229 (2014).

17. Skoulding, N. S. et al. Experimental validation of plant peroxisomal targeting prediction algorithms by systematic comparison of in vivo import efficiency and in vitro PTS1 binding affinity. J. Mol. Biol. 427, 1085-1101 (2015).

18. Ojanperä, S. et al. Isotopic pattern and accurate mass determination in urine drug screening by liquid chromatography/time-of-flight mass spectrometry. Rapid Commun. Mass Spectrom. 20, 1161-1167 (2006)

19. Chowdhary, G., Kataya, A., Lingner, T. \& Reumann, S. Non-canonical peroxisome targeting signals: identification of novel PTS1 tripeptides and characterization of enhancer elements by computational permutation analysis. BMC Plant Biol. 12, 142 (2012).

20. Reumann, S. \& Bartel, B. Plant peroxisomes: recent discoveries in functional complexity, organelle homeostasis, and morphological dynamics. Curr. Opin. Plant Biol. 34, 17-26 (2016).

21. Lingner, T. et al. Identification of novel plant peroxisomal targeting signals by a combination of machine learning methods and in vivo subcellular targeting analyses. Plant Cell. 23, 1556-1572 (2011).

22. Reumann, S., Buchwald, D. \& Lingner, T. PredPlantPTS1: a web server for the prediction of plant peroxisomal proteins. Front. Plant Sci. 3, 194 (2012).

23. Zhang, Y. I-TASSER server for protein 3D structure prediction. BMC Bioinformatics 9, 40 (2008).

24. Roy, A., Kucukural, A. \& Zhang, Y. I-TASSER: a unified platform for automated protein structure and function prediction. Nat. Protoc. 5, 725-738 (2010).

25. Yang, J. et al. The I-TASSER Suite: protein structure and function prediction. Nat. Methods 12, 7-8 (2015).

26. Yang, J. \& Zhang, Y. I-TASSER server: new development for protein structure and function predictions. Nucleic Acids Res. 43, W174-181 (2015).

27. Maynard, E. L., Gatto, G. J. Jr. \& Berg, J. M. Pex5p binding affinities for canonical and noncanonical PTS1 peptides. Proteins 55, 856-861 (2004).

28. Ma, C. \& Reumann, S. Improved prediction of peroxisomal PTS1 proteins from genome sequences based on experimental subcellular targeting analyses as exemplified for protein kinases from Arabidopsis. J. Exp. Bot. 59, 3767-3779 (2008).

29. Decker, E. L. \& Reski, R. The moss bioreactor. Curr. Opin. Plant Biol. 7, 166-170 (2004)

30. Büttner-Mainik, A. et al. Production of biologically active recombinant human factor H in Physcomitrella. Plant Biotechnol. J. 9, 373-383 (2011).

31. Reski, R., Parsons, J. \& Decker, E. L. Moss-made pharmaceuticals: from bench to bedside. Plant Biotechnol. J. 13, 1191-1198 (2015).

32. Nordgren, M. et al. Export-deficient monoubiquitinated PEX5 triggers peroxisome removal in SV40 large T antigen-transformed mouse embryonic fibroblasts. Autophagy 11, 1326-1340 (2015).
33. Kamisugi, Y. et al. Giant peroxisomes in a moss (Physcomitrella patens) peroxisome biogenesis factor 11 mutant. New. Phytol. 209, 576-589 (2016).

34. Liu, Y., Shah, K., Yang, F., Witucki, L. \& Shokat, K. M. Engineering Src family protein kinases with unnatural nucleotide specificity. Chem. Biol. 5, 91-101 (1998).

35. Bornscheuer, U. T. et al. Engineering the third wave of biocatalysis. Nature 485, 185-194 (2012).

36. Baud, M. G. J. et al. A bump-and-hole approach to engineer controlled selectivity of BET bromodomain chemical probes. Science 346, 638-641 (2014).

37. Windle, C. L., Müller, M., Nelson, A. \& Berry, A. Engineering aldolases as biocatalysts. Curr. Opin. Chem. Biol. 19, 25-33 (2014).

38. Speltz, E. B., Nathan, A. \& Regan, L. Design of protein-peptide interaction modules for assembling supramolecular structures in vivo and in vitro. ACS Chem. Biol. 10, 2108-2115 (2015).

39. Aakre, C. D. et al. Evolving new protein-protein interaction specificity through promiscuous intermediates. Cell 163, 594-606 (2015).

40. Bonsor, D. A. \& Sundberg, E. J. Dissecting protein-protein Interactions using directed evolution. Biochemistry 50, 2394-2402 (2011).

41. Yuen, C. M. \& Liu, D. R. Dissecting protein structure and function using directed evolution. Nat. Methods 4, 995-997 (2007).

42. Gouveia, A. M., Guimaraes, C. P., Oliveira, M. E., Sa-Miranda, C. \& Azevedo, J. E. Insertion of Pex5p into the peroxisomal membrane is cargo protein-dependent. J. Biol. Chem. 278, 4389-4392 (2003).

43. Knight, C. D., Cove, D. J., Cuming, A. C. \& Quatrano, R. S. in Molecular Plant Biology Vol. 2 (eds Gilmartin P. M. \& Bowler C.) 285-299 (Oxford University Press, 2002).

\section{Acknowledgements}

We acknowledge funding from the Leverhulme Trust (RPG-2012-516), the BBSRC (BB/I006710/1 for fluorescence microscope) and the Wellcome Trust (WT104918MA for confocal microscope). We thank Katherine Davis for assistance in image classification and Dr Heba Ebeed for the identification of Pp3c18_20320 as a putative PTS1-containing moss protein.

\section{Author contributions}

L.L.C.: Performed peptide synthesis, mutagenesis, protein expression/purification, and fluorescence anisotropy, developed the peptide pull-down screen, and processed results from the peptide identification by mass spectrometry. R.P.: Performed cloning, and optimized and performed moss transformation and in vivo imaging. Y.K.: Performed cloning, moss transformation, and in vivo imaging. A.Be.: Supervised protein expression, protein purification, mutagenesis, and design of mutations within AtPEX5C. A.C.C. Designed constructs and supervised moss transformation studies. A.Ba.: Conceived the project with S.L.W., designed experiments, and coordinated the study. S.L.W.: Devised the peptide pull-down screen, supervised and processed results from the peptide identification by mass spectrometry, and wrote the software for image classification. L.L.C., R.P., S.L.W., A.C.C., and A.Ba.: Wrote the paper. All authors analyzed data, and saw and approved the final version of the manuscript.

\section{Additional information}

Supplementary Information accompanies this paper at doi:10.1038/s41467-017-00487-7.

Competing interests: The authors declare no competing financial interests.

Reprints and permission information is available online at http://npg.nature.com/ reprintsandpermissions/

Publisher's note: Springer Nature remains neutral with regard to jurisdictional claims in published maps and institutional affiliations.

\footnotetext{
Open Access This article is licensed under a Creative Commons Attribution 4.0 International License, which permits use, sharing, adaptation, distribution and reproduction in any medium or format, as long as you give appropriate credit to the original author(s) and the source, provide a link to the Creative Commons license, and indicate if changes were made. The images or other third party material in this article are included in the article's Creative Commons license, unless indicated otherwise in a credit line to the material. If material is not included in the article's Creative Commons license and your intended use is not permitted by statutory regulation or exceeds the permitted use, you will need to obtain permission directly from the copyright holder. To view a copy of this license, visit http://creativecommons.org/ licenses/by/4.0/.
}

(C) The Author(s) 2017 